\title{
Evaluation of micronutrient profile of North Indian children with cystic fibrosis: a case-control study
}

\author{
Krishan Yadav', Meenu Singh', Suresh Kumar Angurana', Savita Verma Attri', Gaurav Sharma', Minni Tageja' and \\ Anil Kumar Bhalla'
}

BACKGROUND: Data on the micronutrient levels in children with cystic fibrosis (CF) are not available from developing countries, wherein the nutritional profile of children is quite different from that of Western countries.

METHODS: Levels of fat-soluble vitamins ( $A, D$, and $E$ ) and trace metals (iron, copper, and zinc) were measured in $27 \mathrm{CF}$ cases and 27 controls.

RESULTS: CF cases had significantly low levels of all studied micronutrients compared with controls, and the levels were even lower in cases with exacerbation than in stable CF cases. Prevalence of deficiency of vitamin D, vitamin E, iron, copper, and zinc was significantly higher in cases than in controls, whereas vitamin A deficiency was almost equal in both the groups.

CONCLUSION: The prevalence of deficiency of vitamins A, D, and $E$ and iron, copper, and zinc was high in CF cases, and their levels were significantly lower in cases than controls. CF cases should be regularly monitored for these micronutrients, and appropriate supplementation should be considered.

C ystic fibrosis (CF) is an autosomal recessive disorder with multiple organ involvement (1). CF is being increasingly recognized in the Indian subcontinent due to increased awareness among pediatricians, although its precise magnitude is not known. The estimated prevalence of CF in the Indian population is $1 / 43,321$ to $1 / 100,323$, and the total number of CF cases in India are estimated to be 12,000-25,000 (2). In 1968, six CF cases were reported from our center for the first time (3).

$\mathrm{CF}$ in Indian children is usually diagnosed late due to nonfamiliarity with the disease and nonavailability of diagnostic tests at all the centers. CF is caused by mutation in the cystic fibrosis transmembrane conductance regulator (CFTR) gene, and $\sim 2,000$ sequence variants have been identified, of which $\Delta \mathrm{F} 508$ is the predominant mutation $(2,4-6)$.

Pancreatic insufficiency is one of the major factors in CF morbidity. It leads to fat and bile malabsorption, which predisposes individuals with $\mathrm{CF}$ at risk for developing severe deficiency of fat-soluble vitamins (A, D, E, and $\mathrm{K}$ ) and altered homeostasis of trace elements such as calcium, magnesium, iron, copper, and zinc, leading to their deficiency as well (7-10). The literature regarding the levels of fat-soluble vitamins and trace elements in CF patients is scanty and inconclusive and is available only from studies carried out in Western countries. No study is available from India, wherein the nutritional profile of children is quite different from that of children in Western countries. It becomes important in such scenarios to collect comprehensive laboratory data and follow up prospectively to formulate effective management guidelines. Therefore, it becomes imperative to study the levels of fat-soluble vitamins, such as A, D, and E, and trace elements, such as iron, copper, and zinc, in our CF patients and to correlate these levels with their clinical status.

We undertook this study to assess the micronutrient profiles in CF cases and to compare these with the micronutrient profiles of healthy controls, clinically stable CF cases, and cases with pulmonary exacerbations. To the best of our knowledge, this is the first study to assess the levels of vitamin A, D, and E and the levels of iron, copper, and zinc in the same cohort of children suffering from $\mathrm{CF}$.

\section{RESULTS}

\section{Demographic and Clinical Features}

The demographic profile and clinical features are described in Table 1. Most of the CF cases showed failure to thrive, recurrent/persistent pneumonia, steatorrhea/malabsorption, and pallor. Only two children had histories of meconium ileus. There was a history of previous sibling death due to respiratory or gastrointestinal problems in four families and consanguinity in two families among cases. Only six (22.2\%) cases were taking pancreatic enzyme supplementation for the past $1 \mathrm{y}$ at the time of sampling. Fecal fat examination (qualitative) revealed steatorrhea in all cases of $\mathrm{CF}$, with $>100$ fat globules per field in all of them.

\section{Vitamins $A, D$, and $E$}

Mean plasma levels of vitamins and trace elements and the number of deficient individuals are depicted in Table 2. Table 3 depicts levels of micronutrients in $\mathrm{CF}$ cases with exacerbation in comparison with the levels in stable CF cases. Mean plasma vitamin A (retinol) levels were found to be significantly lower 
Table 1. Demographic and clinical profile of CF cases and controls

\begin{tabular}{|c|c|c|c|}
\hline Characteristics & $\begin{array}{l}\text { Cases } \\
(n=27)\end{array}$ & $\begin{array}{l}\text { Controls } \\
(n=27)\end{array}$ & $\begin{array}{c}P \\
\text { value }\end{array}$ \\
\hline Age at enrollment (y) & $5.7 \pm 2.5$ & $7.4 \pm 2.7$ & 0.23 \\
\hline Age at onset of symptoms (mo) & $11 \pm 3.3$ & - & - \\
\hline Ratio of boys:girls & $22: 5$ & 19:8 & 0.34 \\
\hline Weight at enrollment $(\mathrm{kg})$ & $19.8 \pm 6.3$ & $25.3 \pm 8.05$ & 0.03 \\
\hline Height at enrollment $(\mathrm{cm})$ & $105 \pm 16.5$ & $123 \pm 16.8$ & 0.04 \\
\hline Failure to thrive, $n(\%)$ & $26(96.3)$ & & \\
\hline Recurrent/persistent pneumonia, $n$ (\%) & $25(92.6)$ & & \\
\hline Steatorrhea/malabsorption, $n(\%)$ & $24(88.9)$ & & \\
\hline Pallor, $n(\%)$ & $20(74.1)$ & & \\
\hline Meconium ileus, $n(\%)$ & $2(7.4)$ & & \\
\hline Bitot's spot, $n(\%)$ & $1(3.7)$ & & \\
\hline Clinical signs of rickets, $n$ (\%) & $1(3.7)$ & & \\
\hline
\end{tabular}

Data are expressed as mean \pm SD.

CF, cystic fibrosis.

Table 2. Micronutrient levels of cases and controls

\begin{tabular}{lccc}
\hline Characteristics & $\begin{array}{c}\text { Cases } \\
(n=27)\end{array}$ & $\begin{array}{l}\text { Controls } \\
(n=27)\end{array}$ & $P$ value \\
\hline Vitamin A deficient, $n(\%)$ & $27(100 \%)$ & $25(92.6 \%)$ & 0.49 \\
Vitamin A level, $\mathrm{nmol} / \mathrm{I}$ & $173 \pm 35$ & $456 \pm 160$ & 0.01 \\
Vitamin D deficient, $n(\%)$ & $26(96.3 \%)$ & $15(55.6 \%)$ & 0.0004 \\
Vitamin D level, $\mathrm{nmol} / \mathrm{l}$ & $44 \pm 18$ & $75.4 \pm 39$ & 0.01 \\
Vitamin E deficient, $n(\%)$ & $9(33.3 \%)$ & $0(0 \%)$ & 0.001 \\
Vitamin E level, $\mu \mathrm{mol} / \mathrm{I}$ & $8.0 \pm 1.0$ & $20 \pm 6.4$ & 0.01 \\
Iron deficient, $n(\%)$ & $13(48.1 \%)$ & $1(3.7 \%)$ & 0.0003 \\
Iron level, $\mu \mathrm{mol} / \mathrm{l}$ & $7.5 \pm 1.2$ & $13 \pm 9.3$ & 0.01 \\
Copper deficient, $n(\%)$ & $12(44.4 \%)$ & $(0)$ & 0.0001 \\
Copper level, $\mu \mathrm{mol} / /$ & $18 \pm 14.3$ & $21 \pm 5.0$ & 0.01 \\
Zinc deficient, $n(\%)$ & $26(96.3)$ & $3(11.1)$ & 0.0001 \\
Zinc level, $\mu \mathrm{mol} / / \mathrm{l}$ & $7.2 \pm 2.3$ & $15 \pm 4$ & 0.04 \\
\hline
\end{tabular}

Data are expressed as numbers $(n(\%))$ and as mean \pm SD.

Table 3. Micronutrient levels among stable CF cases and CF cases during exacerbation

\begin{tabular}{lccc}
\hline Characteristics & $\begin{array}{c}\text { Stable CF } \\
\text { cases }(n=21)\end{array}$ & $\begin{array}{c}\text { CF cases during } \\
\text { exacerbation }(n=6)\end{array}$ & $P$ value \\
\hline Vitamin A $(\mathrm{nmol} / \mathrm{l})$ & $180 \pm 30$ & $150 \pm 86$ & 0.01 \\
Vitamin D $(\mathrm{nmol} / \mathrm{l})$ & $51 \pm 15$ & $18 \pm 6.2$ & 0.02 \\
Vitamin $\mathrm{E}(\mu \mathrm{mol} / \mathrm{l})$ & $9.0 \pm 2.1$ & $8.0 \pm 3.0$ & 0.30 \\
Iron $(\mu \mathrm{mol} / \mathrm{l})$ & $10 \pm 8.4$ & $7.0 \pm 6.0$ & 0.04 \\
Copper $(\mu \mathrm{mol} / \mathrm{l})$ & $21 \pm 15$ & $9.0 \pm 4.0$ & 0.03 \\
Zinc $(\mu \mathrm{mol} / \mathrm{l})$ & $8.0 \pm 4.2$ & $7.0 \pm 1.6$ & 0.09 \\
\hline
\end{tabular}

Data are expressed as mean \pm SD.

CF, cystic fibrosis.

in CF cases as compared with those in the healthy controls ( $P$ value $=0.01)$; in addition, the levels were significantly less in cases with exacerbation as compared with those in stable CF cases $(P$ value $=0.01)$. All the CF cases were vitamin A deficient, and 25 out of 27 controls were also deficient in vitamin A. Clinical sign of vitamin A deficiency was noticed only in one case in the form of Bitot's spot, in which the level of vitamin A was $21 \mu \mathrm{g} / \mathrm{l}(73 \mu \mathrm{mol} / \mathrm{l})$. The plasma vitamin D levels were significantly lower in CF cases than in the control group. Among cases, only one child had sufficient vitamin $\mathrm{D}$, and the remaining children were all vitamin $\mathrm{D}$ deficient. Among controls, $55.6 \%$ were vitamin $\mathrm{D}$ deficient. In cases with exacerbations, vitamin D levels were lower as compared with the levels in stable patients. All patients in the exacerbation group were vitamin $\mathrm{D}$ deficient. One case had signs of vitamin $\mathrm{D}$ deficiency in the form of wrist widening, dental abnormalities, bowing of legs, and frontal bossing, with a vitamin D level of 7 $\mu \mathrm{g} / \mathrm{l}(17.5 \mu \mathrm{mol} / \mathrm{l})$.

Mean plasma vitamin E ( $\alpha$-tocopherol) levels were found to be significantly lower in CF cases as compared with the levels in healthy controls. The mean levels of vitamin $\mathrm{E}$ in stable cases and in cases with exacerbation were not significantly different. Vitamin E deficiency was observed in 33\% of CF cases, and there was no deficiency of vitamin $\mathrm{E}$ in controls.

\section{Iron, Copper, and Zinc}

The mean serum iron levels in cases were significantly lower as compared with the levels in controls. Deficient iron levels were noted in 13 cases and 1 control. Iron levels were lower in $\mathrm{CF}$ cases with exacerbation than in stable CF cases. Moreover, 20 cases had pallor on examination and 13 out of them were iron deficient. The mean hemoglobin level among cases was $11.69 \pm 1.13 \mathrm{~g} / \mathrm{dl}$. There was a significant correlation between the mean hemoglobin and iron levels among patients with $\mathrm{CF}$ $(P$ value $=0.04)$.

Mean serum copper levels in cases and controls, $115 \pm 91 \mu \mathrm{g} /$ $\mathrm{dl}(18 \pm 14.3 \mu \mathrm{mol} / \mathrm{l})$ and $133 \pm 30 \mu \mathrm{g} / \mathrm{dl}(21 \pm 5 \mu \mathrm{mol} / \mathrm{l})$, respectively, were significantly different $(P=0.01)$. Copper deficiency was observed in $44 \%$ of CF cases. None of the controls were copper deficient. In cases with exacerbation of disease, serum copper levels were further low $(57 \pm 25.6 \mu \mathrm{g} / \mathrm{dl}$ or $9 \pm 4 \mu \mathrm{mol} / \mathrm{l})$ as compared with the levels in stable cases $(P$ value $=0.03)$.

Zinc levels were significantly low in patients with CF when compared with the same in controls. Twenty-six cases and three controls were zinc deficient $(P$ value $=0.0001)$. Serum zinc levels in cases with exacerbation were not different from the levels in stable cases $(46 \pm 9.6 \mu \mathrm{g} / \mathrm{dl}(7 \pm 1.6 \mu \mathrm{mol} / \mathrm{l}) \mathrm{vs}$. $51.9 \pm 27.3 \mu \mathrm{g} / \mathrm{dl}(8.0 \pm 4.2 \mu \mathrm{mol} / \mathrm{l} ; P$ value $=0.09))$.

\section{DISCUSSION}

This study demonstrates that the prevalence of deficiency of vitamins $\mathrm{A}, \mathrm{D}$, and $\mathrm{E}$ and of iron, copper, and zinc was high among CF cases. Moreover, the mean levels of all these micronutrients were significantly lower in CF cases when compared with healthy controls.

During the first decade of life, the height and weight in patients with CF are maintained at about 0.5 SD below those of the general population (11). However, we have observed that almost all of our CF cases showed failure to thrive, and the 


\section{Articles | Yadave tal.}

reasons for this failure might be the poor nutritional status of Indian children, effect of the disease, and the fact that fewer cases $(22.2 \%)$ were on pancreatic enzyme supplementation.

About $70-90 \%$ of CF patients suffer from pancreatic insufficiency, which leads to malabsorption and deficiency of major nutrients including the fat-soluble vitamins (A, D, E, and $\mathrm{K}$ ) (7). We observed that biochemical evidence of deficiency of vitamins $\mathrm{A}, \mathrm{D}$, and $\mathrm{E}$ was seen in $100,96.3$, and $33.3 \%$ of cases, respectively, and the levels of these vitamins were significantly lower in CF cases than in controls. The literature regarding prevalence of deficiency of micronutrients in CF children from developing countries, wherein factors such as delay in diagnosis, poor nutrition profile, inadequate treatment measures, poor compliance, and intercurrent infections predominate, is limited. Most of the previous studies reported variable prevalence of deficiencies of fat-soluble vitamins and minerals in cases with CF (12-16). Clinical signs of vitamin A and D deficiency were observed in only one case each, highlighting the importance of monitoring biochemical levels of these vitamins in CF cases.

Vitamin A plays an important role in immunity $(17,18)$ and acts as a potent antioxidant. Increased oxidation and decreased antioxidants together lead to the oxidant/antioxidant imbalance found in CF (7). The most recent survey data obtained from eight states in 2003 suggest that $62 \%$ of preschoolers in India are vitamin A deficient (19). Against this background, vitamin A deficiency found in 100\% of CF cases is explainable. Vitamin D levels in cases with CF are found to be insufficient despite routine supplementation with vitamin $\mathrm{D}$ (15). This may be due to inadequate supplements, incomplete absorption due to exocrine pancreatic insufficiency, accelerated excretion through enterohepatic dumping before exposure to the hepatic 25-hydroxylase enzyme, decreased synthesis (because many CF patients actively avoid sunlight exposure due to photosensitivity from intake of some antibiotics), decreased storage due to decreased levels of vitamin D-binding protein, and less body fat (20). In the context of vitamin E deficiency, exocrine pancreatic insufficiency is not the only underlying mechanism because administration of pancreatic enzymes does not correct biochemical deficiency completely. Vitamin $\mathrm{E}$ is a very important antioxidant and reduces the effects of free oxygen radicals on unsaturated fatty acids and in this process, it is consumed. Lipid peroxidation has been shown to be increased in CF, and this is one of the reasons for the low levels of vitamin $\mathrm{E}$ (21).

We observed that significant numbers of cases were deficient in iron, copper, and zinc, with levels being significantly lower than that in controls. Kelleher et al. (8) measured serum calcium, magnesium, iron, copper, and zinc in $117 \mathrm{CF}$ patients and found that levels of all essential elements (except iron) were well maintained. Ehrhardt et al. (22) described iron deficiency in $32 \%$ ( 41 of 127) of CF cases. Iron deficiency in patients with CF has been attributed to a combination of factors, including chronic inflammation, malabsorption of iron, gastrointestinal blood loss, poor dietary intake, Pseudomonas aeruginosa colonization (which leads to increased iron consumption), and increased production of cytokines (tumor necrosis factor- $\alpha$ and interleukin-8) in response to bacterial infection (which reduces the systemic availability of iron) $(23,24)$. Percival et al. (9) showed that patients with CF are prone to moderate copper deficiency. Akanli et al. (25) found that about one-third of CF patients were deficient in zinc, which is an integral part of many biological enzymes, is a regulator of ion transporters, and exhibits powerful antioxidant activity in several organs including the lungs.

We also observed that all the cases with pulmonary exacerbation were deficient in vitamin $\mathrm{A}$, vitamin $\mathrm{D}$, iron, and copper and had mean levels lower than those in stable CF cases. Increased consumption of antioxidant vitamins and minerals during exacerbation might be the reason. Lagrange-Puget et al. (26) demonstrated that levels of vitamin A, vitamin E, carotenoids, and glutathione were lower in CF patients than in controls and that these levels decreased further during acute exacerbation and increased after treatment with antibiotics. Hakim et al. (27) concluded that an increased number of exacerbations was directly correlated with lower levels of vitamins $\mathrm{A}$ and $\mathrm{E}$.

The CF Foundation recommended supplementation with vitamins $\mathrm{A}, \mathrm{D}, \mathrm{E}$, and $\mathrm{K}$ in patients with $\mathrm{CF}$, beginning shortly after diagnosis, and their blood levels to be measured $\sim 2$ mo after starting supplementation and annually thereafter-and more frequently, if values are abnormal (4). Moreover, a trial of zinc supplementation ( $1 \mathrm{mg}$ of elemental zinc/kg per day in divided doses for $6 \mathrm{mo}$ ) is recommended in those who are not adequately growing despite adequate caloric intake and pancreatic enzyme replacement therapy (4). There are no clearcut recommendations for monitoring of and supplementation with other micronutrients (such as iron, copper, and selenium). Given the fact that most of Indian CF children are deficient in micronutrients and the results of our study, the recommendations of the CF Foundation regarding supplementation and regular monitoring should be followed in India as well. Strategies including supplementation with these micronutrients and monitoring should be evaluated to assess their effects on respiratory and nonrespiratory outcomes. We also found that vitamin $\mathrm{A}$, vitamin $\mathrm{D}$, and zinc deficiencies are also common in healthy controls, which are also major concerns in the general population (28-30).

The major strength of our study is that this was a prospective case-control study with adequate sample size and with age- and sex-matched controls. The results of our study can be generalized to CF children in developing countries. However, confirmation of our findings and evaluation of the effectiveness of supplementation with these vitamins and trace elements are required in well-designed larger prospective studies involving patients from both developed and developing countries. The drawback is that we did not follow levels of these trace elements for long, after supplementation, and after treatment of pulmonary exacerbation. Our study suggests that a large multicenter interventional study for appropriate doses of these micronutrients should be conducted to prevent deficiencies of both fat-soluble vitamins and trace elements in CF patients. 
CF patients may also require dose escalation during exacerbation, and this needs to be studied further.

\section{Conclusion}

Deficiencies of the vitamins A, D, and E and of iron, copper, and zinc were highly prevalent in CF cases, which were further aggravated in cases with exacerbations. From the results of this study, it could be recommended that patients with CF should be regularly monitored for these micronutrients, and appropriate supplementation should therefore be considered, at least when deficient.

\section{METHODS}

\section{Population}

This was a case-control study conducted in the Department of Pediatrics in a tertiary care teaching hospital in North India over a period of 1 y (January 2010-December 2010). Written informed consent was obtained from the parents, and the study was approved by the Institute Ethics Committee of the Postgraduate Institute of Medical Education and Research, Chandigarh, India.

Children with CF in the age group of 3 mo to $12 \mathrm{y}$ diagnosed on the basis of consensus criteria (6) attending Pediatric Pulmonology clinic or admitted in the Pediatric Pulmonology ward were enrolled as cases $(n=27)$. These included both stable CF cases $(n=21)$ and those with pulmonary exacerbation $(n=6)$ with Brasfield score $\geq 7$ or Shwachman-Kulczycki score $\leq 70(31,32)$. Age- and sex-matched healthy children attending Pediatrics outpatient department for minor ailments and vaccination were enrolled as controls $(n=27)$. All CF cases were treated as per Pediatric Pulmonology unit protocols of the department.

Consensus criteria for diagnosis of CF were based on the presence of (i) one or more characteristic clinical features (respiratory, gastrointestinal, or genitourinary), (ii) a history of CF in a sibling, (iii) a positive newborn screening test result plus laboratory evidence of cystic fibrosis transmembrane conductance regulator abnormality, as documented by two elevated sweat chloride concentration results $(>60 \mathrm{mEq} / \mathrm{l})$ obtained on separate days, or (iv) identification of two CF-causing mutations or an abnormal nasal potential difference (6). The sweat chloride test remains the gold standard for $\mathrm{CF}$ diagnosis but does not always give a clear answer as in neonates and infants; moreover, some cases with CF may have sweat chloride concentration $<60 \mathrm{mEq} / \mathrm{l}(5,6)$.

The baseline data were recorded in a prestructured format. Body weight and supine length/height ratio were assessed using standard techniques and instruments. Body weight was measured using an electronic weighing machine with accuracy up to $50 \mathrm{~g}$, supine length (in children aged $<2$ y) was measured using infantometer, and height was recorded using a stadiometer with accuracy up to $1 \mathrm{~mm}$. All anthropometric measurements were taken by two independent trained observers at our Growth Clinic, and the average of the two values was taken.

\section{Sample Collection}

Two milliliters of blood samples from cases and controls were taken in heparinized vials wrapped with an aluminum foil to protect from light for estimation of vitamins; $2 \mathrm{ml}$ blood samples were collected in plain vacutainers for evaluation of trace elements. Blood samples were centrifuged at $3,000 \mathrm{rpm}$ for $15 \mathrm{~min}$, and plasma/serum samples were stored at $-20^{\circ} \mathrm{C}$ until further analysis.

\section{Measurement of Vitamin A, D, and E Levels}

Simultaneous determination of vitamins A, D, and E was carried out in plasma samples by high-performance liquid chromatography with photodiode array ultraviolet detection, as described by Alvarez and De Mazancourt (33). Chromatography was performed on Series 200 HPLC system using TotalChrome Workstation software version v. 6.3.1 (Perkin Elmer, Shelton, CT). The chromatographic separation was achieved by Lichrospher $100 \mathrm{RP}$ C18 column $(5 \mu \mathrm{m}$, $250 \times 4.0 \mathrm{~mm})$ (Merck, Darmstadt, Germany).

\section{Measurement of Copper, Zinc, and Iron Levels}

Serum copper and zinc were estimated using AAnalyst 400 Atomic Absorption Spectrometer (Perkin Elmer) using their instruction manual. The analysis was performed against standards prepared in glycerol to approximate the viscosity characteristics of the diluted samples (five times with deionized water). Iron was analyzed using Dimension RxL Max clinical chemistry analyzer (Siemens Healthcare, Malvern, PA) using dedicated reagents.

Plasma levels of vitamin A $<200 \mu \mathrm{g} / \mathrm{l}$ (700 nmol/l), 25-hydroxyvitamin D $[25(\mathrm{OH}) \mathrm{D}]<30 \mu \mathrm{g} / \mathrm{l}(<75 \mathrm{nmol} / \mathrm{l})$, vitamin $\mathrm{E}<3000 \mu \mathrm{g} / \mathrm{l}$ $(7 \mu \mathrm{mol} / \mathrm{l})$, iron $<22 \mu \mathrm{g} / \mathrm{dl}(<4.0 \mu \mathrm{mol} / \mathrm{l})$, copper $<80 \mu \mathrm{g} / \mathrm{dl}(<12.6$ $\mu \mathrm{mol} / \mathrm{l})$, and zinc $<64 \mu \mathrm{g} / \mathrm{dl}(<9.8 \mu \mathrm{mol} / \mathrm{l})$ were considered deficient (8-10,12-14).

\section{Fecal Fat Examination}

Fecal examination was done in all cases at the time of diagnosis as per unit protocol. Stool samples were examined for neutral fats and split fats as per standard technique $(34,35)$. A positive test was the presence of $\geq 10$ fat globules of $>10 \mu \mathrm{m}$ diameter for neutral fats or $>20 \mu \mathrm{m}$ for split fats per field $(34,35)$.

\section{Statistical Analysis}

Appropriate data entry and statistical analyses were performed on Microsoft Excel 2007 (Microsoft, Redmond, WA) and SPSS software v. 15 (SPSS, Chicago, IL). Descriptive statistics (mean, SD, and percentages) were used for baseline variables. Dichotomous outcomes were compared by $\chi^{2}$ test or Fisher's exact test as applicable. Student's $t$-test was used for continuous variables and for calculating differences among stable CF cases and cases with exacerbation. All tests were two tailed, and $P$ value $<0.05$ was considered significant.

\section{STATEMENT OF FINANCIAL SUPPORT \\ None.}

Disclosure: None.

\section{REFERENCES}

1. Prasad R, Sharma H, Kaur G. Molecular basis of cystic fibrosis disease: an Indian perspective. Indian J Clin Biochem 2010;25:335-41.

2. Kabra SK, Kabra M, Lodha R, Shastri S. Cystic fibrosis in India. Pediatr Pulmonol 2007;42:1087-94.

3. Mehta S, Wadhwa UN, Mehta SK, Chhuttani PN. Fibrocystic disease of pancreas in India. Indian Pediatr 1968;5:185-91.

4. Farrell PM, Rosenstein BJ, White TB, et al.; Cystic Fibrosis Foundation. Guidelines for diagnosis of cystic fibrosis in newborns through older adults: Cystic Fibrosis Foundation consensus report. J Pediatr 2008;153:S4-S14.

5. Sharma N, Singh M, Kaur G, Thapa BR, Prasad R. Identification and characterization of CFTR gene mutations in Indian CF patients. Ann Hum Genet 2009;73:26-33.

6. Rosenstein BJ, Cutting GR. The diagnosis of cystic fibrosis: a consensus statement. Cystic Fibrosis Foundation Consensus Panel. J Pediatr 1998;132:589-95.

7. Carr SB, McBratney J. The role of vitamins in cystic fibrosis. J R Soc Med 2000;93:Suppl 38:14-9.

8. Kelleher J, Goode HF, Field HP, Walker BE, Miller MG, Littlewood JM. Essential element nutritional status in cystic fibrosis. Hum Nutr Appl Nutr 1986;40:79-84.

9. Percival SS, Kauwell GP, Bowser E, Wagner M. Altered copper status in adult men with cystic fibrosis. J Am Coll Nutr 1999;18:614-9.

10. Tangpricha V, Kelly A, Stephenson A, et al.; Cystic Fibrosis Foundation Vitamin D Evidence-Based Review Committee. An update on the screening, diagnosis, management, and treatment of vitamin D deficiency in individuals with cystic fibrosis: evidence-based recommendations from the Cystic Fibrosis Foundation. J Clin Endocrinol Metab 2012;97:1082-93.

11. Morison S, Dodge JA, Cole TJ, et al. Height and weight in cystic fibrosis: a cross sectional study. UK Cystic Fibrosis Survey Management Committee. Arch Dis Child 1997;77:497-500.

12. Sokol RJ, Reardon MC, Accurso FJ, et al. Fat-soluble-vitamin status during the first year of life in infants with cystic fibrosis identified by screening of newborns. Am J Clin Nutr 1989;50:1064-71. 
13. Neville LA, Ranganathan SC. Vitamin D in infants with cystic fibrosis diagnosed by newborn screening. J Paediatr Child Health 2009;45:36-41.

14. Bines JE, Truby HD, Armstrong DS, Carzino R, Grimwood K. Vitamin A and $\mathrm{E}$ deficiency and lung disease in infants with cystic fibrosis. J Paediatr Child Health 2005;41:663-8.

15. Rovner AJ, Stallings VA, Schall JI, Leonard MB, Zemel BS. Vitamin D insufficiency in children, adolescents, and young adults with cystic fibrosis despite routine oral supplementation. Am J Clin Nutr 2007;86:1694-9.

16. Farrell PM, Bieri JG, Fratantoni JF, Wood RE, di Sant'Agnese PA. The occurrence and effects of human vitamin E deficiency. A study in patients with cystic fibrosis. J Clin Invest 1977;60:233-41.

17. Ross AC. Vitamin A status: relationship to immunity and the antibody response. Proc Soc Exp Biol Med 1992;200:303-20.

18. Semba RD, Muhilal, Ward BJ, et al. Abnormal T-cell subset proportions in vitamin-A-deficient children. Lancet 1993;341:5-8.

19. World Health Organization. Global prevalence of vitamin A deficiency in populations at risk 1995-2005, 2009. (http://whqlibdoc.who.int/publications/2009/9789241598019_eng.pdf).

20. Hall WB, Sparks AA, Aris RM. Vitamin d deficiency in cystic fibrosis. Int J Endocrinol 2010;2010:218691.

21. Benabdeslam H, Abidi H, Garcia I, Bellon G, Gilly R, Revol A. Lipid peroxidation and antioxidant defenses in cystic fibrosis patients. Clin Chem Lab Med 1999;37:511-6.

22. Ehrhardt P, Miller MG, Littlewood JM. Iron deficiency in cystic fibrosis. Arch Dis Child 1987;62:185-7.

23. Reid DW, Withers NJ, Francis L, Wilson JW, Kotsimbos TC. Iron deficiency in cystic fibrosis: relationship to lung disease severity and chronic Pseudomonas aeruginosa infection. Chest 2002;121:48-54.

24. Khair OA, Davies RJ, Devalia JL. Bacterial-induced release of inflammatory mediators by bronchial epithelial cells. Eur Respir J 1996;9:1913-22.
25. Akanli L, Lowenthal DB, Gjonaj S, Dozor AJ. Plasma and red blood cell zinc in cystic fibrosis. Pediatr Pulmonol 2003;35:2-7.

26. Lagrange-Puget M, Durieu I, Ecochard R, et al. Longitudinal study of oxidative status in 312 cystic fibrosis patients in stable state and during bronchial exacerbation. Pediatr Pulmonol 2004;38:43-9.

27. Hakim F, Kerem E, Rivlin J, et al. Vitamins A and E and pulmonary exacerbations in patients with cystic fibrosis. J Pediatr Gastroenterol Nutr 2007;45:347-53.

28. Arlappa N, Laxmaiah A, Balakrishna N, Harikumar R, Brahmam GN. Clinical and sub-clinical vitamin A deficiency among rural pre-school children of Maharashtra, India. Ann Hum Biol 2008;35:606-14.

29. Goswami R, Gupta N, Goswami D, Marwaha RK, Tandon N, Kochupillai N. Prevalence and significance of low 25-hydroxyvitamin D concentrations in healthy subjects in Delhi. Am J Clin Nutr 2000;72:472-5.

30. Kapil U, Jain K. Magnitude of zinc deficiency amongst under five children in India. Indian J Pediatr 2011;78:1069-72.

31. Freire ID, Abreu E Silva FA, Araújo MA. Comparison among pulmonary function test results, the Shwachman-Kulczycki score and the Brasfield score in patients with cystic fibrosis. J Bras Pneumol 2008;34:280-7.

32. Hafen GM, Ranganathan SC, Robertson CF, Robinson PJ. Clinical scoring systems in cystic fibrosis. Pediatr Pulmonol 2006;41:602-17.

33. Alvarez JC, De Mazancourt P. Rapid and sensitive high-performance liquid chromatographic method for simultaneous determination of retinol, alpha-tocopherol, 25-hydroxyvitamin D3 and 25-hydroxyvitamin D2 in human plasma with photodiode-array ultraviolet detection. J Chromatogr B Biomed Sci Appl 2001;755:129-35.

34. Teh LB, Stopard M, Anderson S, et al. Assessment of fat malabsorption. J Clin Pathol 1983;36:1362-6.

35. Luk GD. Screening for steatorrhea. Gastroenterology 1979;77:205-6. 